\title{
DETEKSI BORAKS PADA BAKSO BERBASIS IMAGE DENGAN MENGGUNAKAN GAUSSIAN CLASSIFIER
}

\author{
Irwan Budi Santoso \\ Jurusan Teknik Informatika, Sains dan Teknologi \\ Universitas Islam Negeri (UIN) Maulana Malik Ibrahim Malang \\ irwan.budi331177@gmail.com
}

\begin{abstract}
Abstrak- Bakso adalah salah satu makanan yang bergizi tinggi dan banyak dikonsumsi oleh masyarakat. Adanya kompetisi pasar, dan harga daging yang relatif mahal menimbulkan persaingan tidak sehat yang merugikan konsumen, yaitu pemberian bahan tambahan pegawet boraks yang dapat mengganggu kesehatan. Secara kasat mata sulit membedakan bakso boraks dan non-boraks dan untuk mendeteksinya bisa dilakukan secara laboratorium dan dilakukan oleh ahlinya. Berdasarkan hal tersebut, dilakukan penelitian bagaimana membangun aplikasi deteksi boraks pada bakso berdasarkan image-nya yang diambil dengan kamera digital. Salah satu metode untuk mendeteksi objek berdasarkan image-nya adalah Gaussian Classifier yang mensyaratkan fitur objek berdistribusi Multivariate Normal (Gaussian) dan dengan menggunakan peluang bersayarat dapat dihasilkan fungsi diskriminan. Langkah-langkah dalam mendeteksi boraks berdasarkan image-nya dibagi dua tahap yaitu tahap training dan testing. Tahap training meliputi penentuan sampel image objek bakso, merubah image RGB ke grayscale, dan melakukan estimasi parameter distribusi fitur objek. Sedangkan tahap testing meliputi select image objek bakso yang diuji, merubah image ke grayscale, deteksi boraks boraks dengan fungsi diskriminan dan hasil estimasi parameter distribusi. Hasil training menunjukan ada 4 fungsi diskriminan untuk mendeksi boraks pada bakso. Sedangkan hasil testing dari 70 sampel bakso eksperimen (20 non-boraks, 50 boraks), sistem dapat mendeteksi dengan akurasi 71,4286\%.
\end{abstract}

Kata Kunci: Bakso, Boraks, Fitur, Image, Distribusi Multivariate Normal, Gaussian Classifier

\section{PENDAHULUAN}

Beberapa penelitian terkait kandungan boraks pada bakso secara laboratorium telah banyak dilakukan, akan tetapi penelitian terkait deteksi boraks pada bakso secara otomisasi belum begitu banyak dilakukan. Beberapa penelitian kandungan boraks pada bakso secara laboratorium diantaranya adalah yang pernah dilakukan oleh Anissa (2011), dengan metode spektrofotometri, Yeni (2004) di kabupaten Wonogiri, Dandik Widayat (2011) menguji kandungan boraks dalam bakso di kecamatan Sumbersari Jember, Pramutia Sultan (2013) di SDN Mangkura Makasar dengan metode nyala api, Indra Tubagus (2013), penelitian terkait lainnya adalah identifikasi dan penetapan kadar borak dalam bakso di kota Manado, dan Mela (2013) melakukan analisis boraks pada bakso di daerah Tenggilis Mejoyo Surabaya dengan metode nyala api. Penelitian yang berbeda dilakukan oleh Tria Yulli Andariska (2013) yaitu membuat alat untuk mendeteksi bakso yang terkontaminasi boraks dengan menggunakan sensor cahaya berbasis mikrokontroler. Hasil penelitian ini menunjukan, alat deteksi lebih stabil pada kadar boraks di atas 3\% serta alat deteksi bekerja dengan baik pada kadar boraks di atas 4\%. Berbeda lagi dengan penelitian yang dilakukan oleh Irwan (2014b) yaitu deteksi boraks pada bakso berbasis image berdasarkan sensor kamera digital, dengan menggunakan metode Tree-Augmented
Nä̈ve Bayes Network Classifier (TAN), hasilnya menunjukkan secara umum tingkat akurasi dalam mendeteksi boraks pada bakso adalah $85,7 \%$ dan sudah mampu mendeteksi boraks pada bakso dengan kadar $1 \%$. Metode TAN yang digunakan dalam penelitian tersebut relatif kompleks sehingga pada penelitian ini, akan dicoba metode Gaussian Classifier yang proses komputasinya relatif lebih sederhana, namum akan dioptimalkan dalam mengestimasi parameter fitur objeknya sehingga tingkat akurasinya tidak berbeda jauh.

\section{DISTRIBUSI MULTIVARIATE NORMAL (GAUSSIAN)}

Bila diketahui objek image, dengan fitur objek adalah $x$ yang mengikuti distribusi Multivariate Normal (Gaussian) dengan parameter mean ( $\mu$ ) dan covariance $\left(\sum\right)$ (ditulis $x \sim N(\mu, \Sigma)$ ), maka probability density function ( $p d f$ ) (Andrew, 2011; Irwan, 2014a) dari fitur $x$ didefiniskan

$$
\begin{aligned}
& p(x \mid \mu, \Sigma)= \\
& \frac{1}{(2 \pi)^{d / 2}|\Sigma|^{1 / 2}} \exp \left\{-\frac{1}{2}(x-\mu)^{T} \Sigma^{-1}(x-\mu)\right\}
\end{aligned}
$$

dengan $d$ adalah dimensi fitur objek (image). 


\section{A. PENDUGAAN PARAMETER DISTRIBUSI \\ MULTIVARIATE NORMAL (GAUSSIAN)}

Fitur Objek diasumsikan mengikuti distribusi Multivariate Normal (Gaussian) dan pendugaan parameter distribusinya dilakukan dengan menggunakan metode Maximum Likelihood yaitu dengan memaksimumkan fungsi likelihood terhadap parameter distribusi $\theta=(\mu, \Sigma)$. Bila diketahui sampel fitur objek, $\left\{x_{1}, \ldots, x_{n}\right\}, \quad x_{i} \in R^{d}$ dan dengan asumsi bahwa setiap fitur bersifat independen maka fungsi likelihood fitur tersebut (Andrew, 2011) adalah

$$
L\left(\theta, x_{1}, \ldots, x_{2}\right)=\prod_{I=1}^{n} \frac{1}{(2 \pi)^{d / 2}|\Sigma|^{1 / 2}} \exp \left\{-\frac{1}{2}(x-\mu)^{T} \Sigma^{-1}(x-\mu)\right\}
$$

Untuk mempermudah dalam memaksimum-kan fungsi tersebut dapat dilakukan dengan melogaritmakan fungsi pada persamaan 2. Langkah selanjutnya adalah memaksimum-kan fungsi $\log (L)$ dengan cara melakukan deferensial fungsi tersebut terhadap paramater $\mu$ dan $\sum$ dan disama dengankan dengan nol. Sehingga didapatkan parameter mean distribusi (Irwan, 2014a) sebagai berikut

$\hat{\mu}=\frac{1}{n} \sum_{i=1}^{n} x_{i}$

serta hasil pendugaan parameter matrik covariance adalah sebagai berikut

$$
\hat{\Sigma}=\frac{1}{n-1} \sum_{i=1}^{n}(x-\mu)(x-\mu)^{T}
$$

\section{B. FUNGSI DISKRIMINAN}

Dasar yang digunakan untuk membangun fungsi diskriminan adalah peluang bersyarat (irwan, 2014a). Bila diketahui $\omega_{j}$ adalah data fitur kelas $j$, dan $x$ adalah fitur objek (pattern $x$ ), maka peluang bersyarat $\omega_{j}$ bila diketahui $x$ adalah

$$
p\left(\omega_{j} \mid x\right)=\frac{p\left(\omega_{j}\right) p\left(x \mid \omega_{j}\right)}{p(x)}
$$

Nilai $p\left(\omega_{j} \mid x\right)$ equivalen dengan nilai $\log \left(p\left(\omega_{j} \mid x\right)\right)$, sehingga:

$$
\begin{aligned}
& \log \left(p\left(\omega_{j} \mid x\right)\right)=\log \left(\frac{p\left(\omega_{j}\right) p\left(x \mid \omega_{j}\right)}{p(x)}\right) \\
& =\log \left(p\left(x \mid \omega_{j}\right)\right)+\log \left(p\left(\omega_{j}\right)\right)-\log (p(x))
\end{aligned}
$$

Karena nilai $p(x)$ sama untuk semua kelas maka selanjutnya dapat dibangun fungsi diskriminan sebagai berikut:

$$
g_{j}(x)=\log \left(p\left(x \mid \omega_{j}\right)\right)+\log \left(p\left(\omega_{j}\right)\right)
$$

Berdasarkan persamaan 6, maka aturan untuk mengklasifikasikan pattern $x$ adalah

$$
\hat{c}=\arg \max _{c}\left(g_{j}(x)\right), j=1, \ldots, C
$$

dengan $\hat{c}$ adalah kelas objek yang terpilih.

Bila diketahui $\omega_{j}$ adalah vektor fitur pada kelas $j$ yang mengikuti distribusi Multivariate Normal dengan parameter mean vektor $\mu_{j}$ dan matrik covariance $\Sigma_{j}$ maka dengan mengunakan probabilitas bersayarat pattern $x$ bila diketahui $\omega_{j}$ didapatkan fungsi diskriminan (Irwan, 2014a) sebagai berikut

$$
g_{j}(x)=\log \left(p\left(\omega_{j}\right)\right)-\frac{1}{2} \log \left(\left|\sum_{j}\right|\right)-\frac{1}{2}\left(x-\mu_{j}\right)^{T} \sum_{j}^{-1}\left(x-\mu_{j}\right)
$$

Nilai $\mu_{j}$ dan $\sum_{j}$ selanjutnya diganti dengan nilai hasil estimasi berdasarkan data training seperti pada persamaan 3 dan 4. Sehingga didapat fungsi diskriminan atau Gaussian Classifier sebagai berikut $g_{j}(x)=\log \left(p\left(\omega_{j}\right)\right)-\frac{1}{2} \log \left(\left|\hat{\Sigma}_{j}\right|\right)-\frac{1}{2}\left(x-\hat{\mu}_{j}\right)^{T} \hat{\Sigma}_{j}^{-1}\left(x-\hat{\mu}_{j}\right)$ (10) Dengan $p\left(\omega_{j}\right)=n_{j} / \sum_{i=1}^{C} n_{i}$, $n_{j}$ adalah banyaknya data pada kelas $j$.

\section{METODE PENELITIAN}

Tahapan-tahapan secara umum pada penelitian ini meliputi 4 proses yaitu perancangan dan pengumpulan data, desain sistem, implementasi sistem (coding), uji coba sistem yang dibangun.

Data yang digunakan dalam penelitian ini adalah data sekunder yaitu data hasil eksperimen pada penelitian sebelumnya (Irwan, 2014b). Data bakso hasil penelitian sebelumnya adalah bakso daging sapi dengan perlakuan kadar boraks yang berbeda-beda yaitu 1) bakso non-boraks 2) bakso boraks $1 \%$ 3) bakso boraks 3\% 4) bakso boraks 5\%. Masing-masing bakso dengan perlakuan kadar boraks berbeda-beda diambil sampel secukupnya (15 objek setiap perlakuan), begitu juga dengan bakso normal (tanpa boraks) lihat Gambar 1.

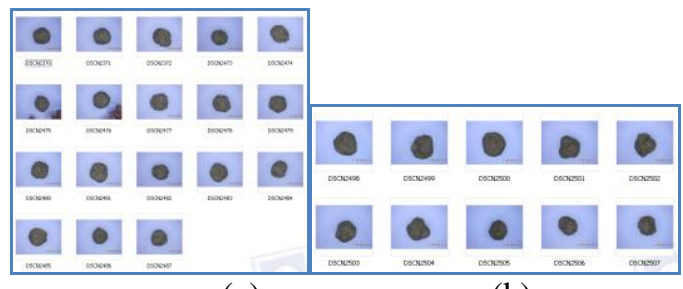

(a) 


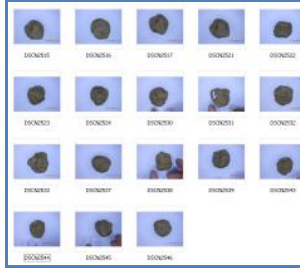

(c)

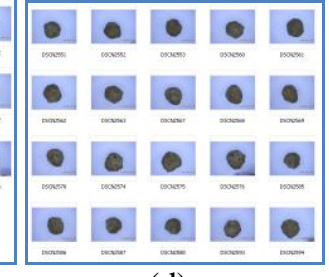

(d)
Gambar 1. Contoh Sampel Bakso (a) no-boraks,(b) boraks-1\%, (c) boraks-3\% (d) boraks-5\% (Irwan, 2014b)

Desain sistem dalam penelitian ini meliputi bagian training/pembelajaran dan bagian testing (pengujian) seperti telihat pada Gambar 2. Pada proses training, langkah pertama adalah melakukan preproses, yang sebelumnya dilakukan proses cropping image terhadap image bakso yang telah diambil berdasarkan hasil pada perancangan dan pengumpulan data, kemudian dilakukan ekstraksi fitur untuk mendapat ciri objek yang mewakili (Irwan, 2014b). Setelah dilakukan ekstraksi selanjutnya dilakukan estimasi parameter distribusi fitur objek dan hasilnya juga disimpan. Sedang pada proses testing, langkah pertama adalah melakukan preproses, yang sebelumnya dilakukan proses cropping image bakso testing, kemudian ekstraksi fitur dan langkah terakhir adalah proses deteksi boraks pada

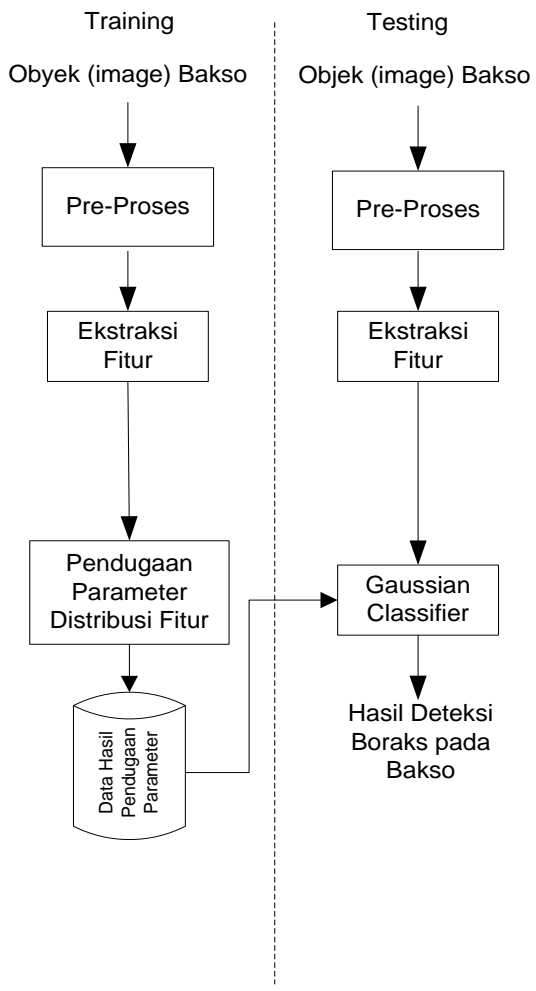

Gambar 2.Proses Training dan Testing

Deteksi Boraks pada Bakso dengan Gaussian Classifier

Bakso berdasarkan fungsi diskriminan dan hasil estimasi parameter distribusi fitur.
Untuk membangun Gaussian Classifier dilakukan dengan membangun fungsi diskriminan sebagaimana bisa dilihat secara rinci pada Algoritma gj (Irwan, 2014a).

ALGORITMA gj ( $\mathrm{x}, \mathrm{mu}$, sigma,nj,C)

//input: $\boldsymbol{x}$ adalah pattern $x$ berdasarkan //ekstraksi fitur objek testing

//input: mu, sigma adalah hasil pendugaan //parameter mean vektor dan matrik //covariance pada setiap kelas berdasarkan //data training

//input: nj, C adalah banyak data pada //setiap kelas pada data training, banyak //kelas objek

//output: gjx, kelas adalah nilai diskriminan //pada setiap kelas objek, hasil pengenalan

//menghitung total banyaknya data pada //seluruh kelas

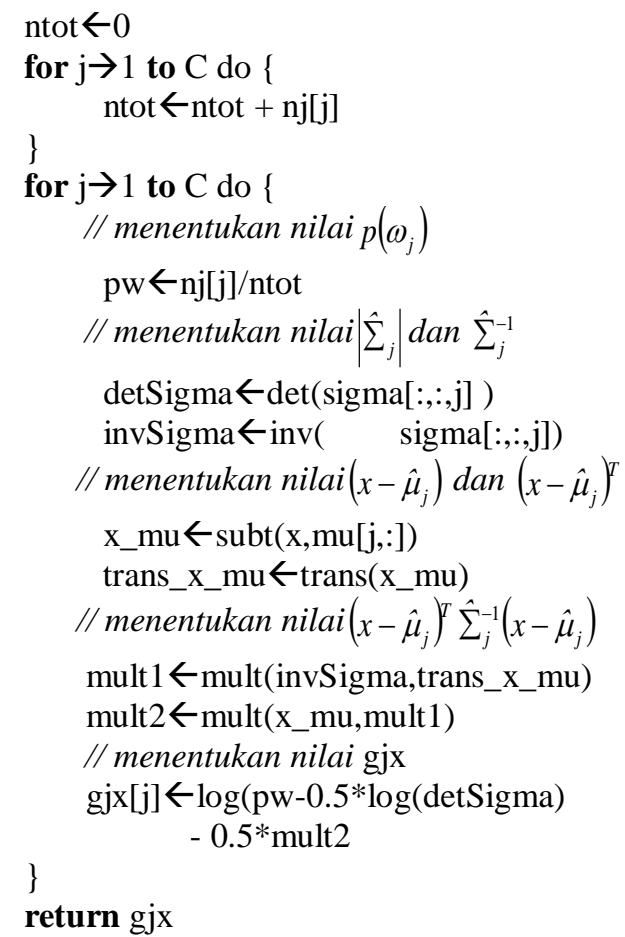

Dalam membaca Algoritma gj adalah ada fungsi-fungsi tambahan yang harus dibuat terlebih dahulu diantaranya fungsi det untuk menentukan nilai determinan, fungsi inv untuk menentukan nilai invers, fungsi subt untuk pengurangan dua buah matrik, fungsi trans untuk mentranspose suatu matrik, fungsi mult untuk mengalikan dua buah matrik (Irwan,2014a).

\section{HASIL DAN PEMBAHASAN}

Ada 4 proses training untuk estimasi parameter distribusi fitur (diasumsikan Multivariate Normal) bakso dalam bentuk image diantaranya data bakso non boraks dengan bakso boraks $1 \%$, bakso non boraks dengan bakso boraks $3 \%$, bakso non boraks dengan bakso boraks 5\%, dan bakso boraks $1 \%$ dengan bakso boraks 3\% dengan bakso boraks $5 \%$. Selanjutnya dari ke 4 hasil estimasi parameter distribusi tersebut dibangun fungsi diskriminan 
(Gaussian Classifier), selanjutnya dari 4 fungsi tersebut diujicobakan terhadap data testing image bakso untuk dideteksi apakah bakso mengandung boraks apa tidak.

Hasil optimalisasi ukuran (dimensi) image objek bakso training antara bakso non-boraks dengan bakso boraks $1 \%$, adalah pada dimensi objek image $3 \times 4,3 \times 2$, $2 \times 5$ dan untuk proses deteksi akan digunakan dimensi image objek 3x4. Untuk bakso training bakso nonboraks dengan bakso boraks $3 \%$ hasil optimalisasi menunjukkan dimensi objek image akan optimal pada dimensi $2 \times 4,4 \times 3,2 \times 5$, dan yang akan digunakan pada proses deteksi adalah pada dimensi image objek 4x3. Hasil optimalisasi ukuran image objek bakso training bakso non-boraks dengan bakso boraks 5\%, hasil menunjukkan ukuran atau dimensi image yang paling optimal adalah pada dimensi image objek $3 \times 4,2 \times 5,2 \times 4,3 \times 5$ dan yang digunakan adalah pada deteksi objek adalah 3x4. Sedangkan hasil optimalisasi ukuran image objek bakso training antara bakso boraks $1 \%$ dengan bakso boraks $3 \%$ dengan bakso boraks $5 \%$ pada ukuran atau dimensi image objek $3 \times 4$. Demikian halnya untuk optimalisasi ukuran image objek bakso training ,bakso non-boraks dengan boraks $1 \%$ dengan bakso boraks $3 \%$ dengan bakso boraks $5 \%$ diperoleh ukuran atau dimensi yang optimal adalah 3x4 dengan akurasi 98,333\%.

Dengan menggunakan ukuran atau dimensi objek image training yang optimal, selanjutnya dilakukan estimasi parameter distribusi masing-masing kelas training dan menghasilkan 4 fungsi diskriminan untuk mendeteksi boraks pada bakso. Hasil uji coba terhadap 70 data testing (20 bakso non-boraks dan 50 bakso boraks) menunjukkan akurasi dalam mendeteksi bakso boraks adalah $71,4286 \%$.

\section{KESIMPULAN}

Langkah-Langkah membangun aplikasi deteksi boraks pada bakso berdasarkan image bakso antara lain pertama membangun apliaksi akusisi data image objek bakso, kedua membangun aplikasi preproses untuk merubah image objek bakso menjadi grayscale, ketiga mebangun aplikasi training data untuk mendapatkan estimasi parameter distribusi fitur objek image bakso, dan terakhir membangun aplikasi deteksi boraks pada bakso dengan menggunakan fungsi diskriminan dan parameter hasil estimasi parameter. Hasil uji coba menunjukkan dari 70 sampel bakso yang terdiri dari 20 sampel bakso non-boraks dan 50 sampel bakso boraks, dengan menggunakan Gaussian Classifier secara umum sampel dapat dideteksi dengan akurasi $71,4286 \%$.

\section{REFERENSI}

[1] Andrew, 2011," Statistical pattern recognition" ,Third Edition, John Wiley \& Sons, Ltd

[2] Annisa, 2011, "Identifikasi dan Penetapan Kadar Natrium Tetraboraks dengan Metode Titrasi Asam Basa dan Spektrofotometri Sinar Tampak Dalam
Bakso Daging Sapi “,Skripsi, Fakultas Farmasi, Universitas Sumatra Utara

[3] Alexsander, 2004, "Testing the assumption of multivariate normality", Psychology Science, Volume 46, p. 243-258, Michigan State University, Department of Psychology, USA

[4] Dandik, W., 2011, "Uji Kandungan Boraks pada Bakso (Studi pada Warung Bakso di Kecamatan Sumbersari Kabupaten Jember", Skripsi, Fakultas Kesehatan, Universitas Jember.

[5] Indra, T., Gayatri C., Fatimawali, 2013, "Indentifikasi Dan Penetapan Kadar Boraks Dalam Bakso Jajanan di Kota Manado", Jurnal Ilmiah Farmasi (PHARMACON)-UNSRAT Vol.2.No.04.

[6] Irwan, 2012, "Model Pengenalan Terbaik Dengan Tree-Augmented Network (TAN) dan Estimator Maximum Likelihood (ML) Berdasarkan Fitur Objek“, Jurnal MATICS, No. 5, Vol. 4, Halaman 197-203, Teknik Informatika UIN Maulana Malik Ibrahim Malang

[7] Irwan, 2013,"Mutual Information Dalam Mengenali Objek Dengan Fitur Berdistribusi Bivariate Gaussian” Jurnal MATICS, No. 2, Vol. 5, Halaman 119-124, Teknik Informatika UIN Maulana Malik Ibrahim Malang

[8] Irwan, 2014a,"Membangun Gaussian Classifier dalam Mengenali Objek Dalam Bentuk Image" Jurnal MATICS, No. 1, Vol. 1, Halaman 1-53, Teknik Informatika UIN Maulana Malik Ibrahim Malang

[9] Irwan, 2014b, Deteksi Boraks pada Bakso Berbasis Image dengan Menggunakan TreeAugmeneted Bayesian Network (TAN), Penelitian Kompetitif Dosen LP2M UIN Malang.

[10] Mela, S.S., 2013, "Analisis Boraks Dalam Bakso Daging Sapi A dan B di Daerah Tenggilis Mejoyo Surabaya Menggunakan Spektrofotometri", Jurnal Ilmiah Mahasiswa Universitas Surabaya Vol.2 No.2.

[11] Pramutia, S., 2013, "Analisis Kandungan Zat Pengawet Jajanan Bakso di SDN Kompleks Makassar", Program Studi Ilmu Gizi Fakultas Kesehatan Masyarakat, Universitas Hasanuddin Makassar

[12] Tria, Y. A., 2013, "Rancang Bangun Alat Deteksi Bakso Daging Terkontaminasi Boraks Dengan Menggunakan Sensor Cahaya TSL230 Berbasis Mikrokontroler ATMEGA8", Skripsi Program Studi Fisaka Fakultas Sains dan Teknologi Universitas Islam Negeri Sunan Kalijag Yogyakarta.

[13] Yeni, U., 2004, "Studi Identifikasi Kandungan Boraks pada Bakso yang Diproduksi di Kabupaten Wonogiri, Thesis", Universitas Diponegoro. 